\title{
The PGI enzyme system and fitness response to temperature as a measure of environmental tolerance in an invasive species.
}

In the field of invasion ecology, the determination of a species' environmental tolerance, is a key parameter in the prediction of its potential distribution, particularly in the context of global warming. In poikilothermic species such as insects, temperature is often considered the most important abiotic factor that affects numerous life-history and fitness traits through its effect on metabolic rate. Therefore the response of an insect to challenging temperatures may provide key information as to its climatic and therefore spatial distribution. Variation in the phosphoglucose-6-isomerase (PGI) metabolic enzyme-system has been proposed in some insects to underlie their relative fitness, and is recognised as a key enzyme in their thermal adaptation. However, in this context it has not been considered as a potential mechanism contributing to a species invasive cability. The present study aimed to compare the thermal tolerance of an invasive scarabaeid beetle, Costelytra zealandica (White) with that of the closely related, and in part sympatrically occurring, congeneric non-invasive species C. brunneum (Broun), and to consider whether any correlation with particular PGI phenotypes was apparent. Third instar larvae of each species were exposed to one of three different temperatures $\left(10,15\right.$ and $\left.20^{\circ} \mathrm{C}\right)$ over six weeks and their fitness (survival and growth rate) measured and PGI phenotyping performed via cellulose acetate electrophoresis. No relationship between PGI phenotypes and fitness was detected, suggesting that PGI may not be contributing to the invasion success and pest status of $C$. zealandica. 
1 Marie-Caroline LEFORT*, Bio-Protection Research Centre, PO Box 85084, Lincoln University,

2 Lincoln 7647, Christchurch, New Zealand.

3 Samuel BROWN, Bio-Protection Research Centre, PO Box 85084, Lincoln University, Lincoln 7647,

4 Christchurch, New Zealand.

5 Stéphane BOYER, Bio-Protection Research Centre, PO Box 85084, Lincoln University, Lincoln 7647,

6 Christchurch, New Zealand. Department of Ecology, Faculty of Agricultural and Life Sciences PO Box

7 85084, Lincoln University, Lincoln 7647, New Zealand.

8 Susan WORNER, Bio-Protection Research Centre, PO Box 85084, Lincoln University, Lincoln 7647,

9 Christchurch, New Zealand.

10 Karen ARMSTRONG, Bio-Protection Research Centre, PO Box 85084, Lincoln University, Lincoln

11 7647, Christchurch, New Zealand

12 *Corresponding author, Marie-Caroline.Lefort@lincolnuni.ac.nz, Ph: +64 3325 3696, Fax: +64 3325

$13 \quad 3864$ 


\section{Introduction}

15 Understanding environmental tolerance is a key factor in predicting a species' potential geographic 16 and ecological range. This in turn is important for the successful management of invasive species. In 17 insect species thermal tolerance is especially important, with extreme temperatures known to affect 18 their development and influence their population dynamics (Wallner 1987, Clarke 2003, Sinclair et al. 19 2012). Direct effects on metabolic rate impact on a number of life-history and fitness traits (Clarke 20 2003, Karl et al. 2008), among which survival and growth (Folguera et al. 2010) are the most 21 important. For instance, McMillan et al. (2005) reported a significant increase in larval mortality of the 22 leaf beetle Chrysomela aeneicollis Schaeffer in the coldest of three river drainages tested, which was 23 exposed to subzero night-time air temperature. Similarly, Kallioniemi and Hanski (2011) reported low

24 survival rates with larvae of the Glanville fritillary butterfly Melitaea cinxia (Linnaeus) subjected to low 25 temperature stress. High temperatures can be equally detrimental as demonstrated by Papanikolaou 26 et al. (2013), where development of the immature stages of the 14-spotted ladybird beetle Propylea 27 quatuordecimpunctata (Linnaeus) was greatly impaired and high mortality rates recorded at the two 28 highest temperatures tested in their study. In fact, temperature is considered the most important 29 abiotic factor affecting the success of phytophagous insects (Bale et al. 2002). Not surprisingly it has 30 also been suggested that invasive species may have a broader and greater physiological tolerance of 31 temperatures than native species sharing the same habitat (for a review see Zerebecki \& Sorte 32 2011). Therefore, knowledge of the effect of challenging or extreme temperatures on invasive insect 33 species could provide key information towards developing spatial and climatic distribution projections 34 for a range of risk assessment applications, and particularly in the context of global warming.

35 An opportunity to test this is presented here by a comparison of the invasive scarab Costelytra 36 zealandica (White) (Scarabaeidae: Melolonthinae) with the closely related non-invasive species $C$.

37 brunneum. These insects are endemic to New Zealand and also occur sympatrically in several 38 places (Given 1966, Lefort et al. 2012, 2013). The extended geographical occurrence of $C$. 39 zealandica, and its severe negative impact on agro-ecosystems, suggests that it has reached a high 40 degree of invasiveness within its home range. In fact, based on early observations, this species 41 seems to have become so widespread that it is only absent from a few remote locations of New 
42 Zealand (Given 1966) and not reached the status of invader for few others (East et al. 1981). This

43 greatly contrasts with the restricted geographical range of $C$. brunneum which remains confined to a

44 few patchy areas throughout New Zealand, essentially located in the New Zealand Southern Alps 45 (Lefort 2013).

46 The widespread distribution of $C$. zealandica in New Zealand is likely to be, in part, related to its 47 tolerance of the wide range of soil temperatures within the array of those encountered throughout 48 New Zealand (Lefort 2013), from sun-baked pastural environments to alpine reaches. As recently 49 suggested by Sinclair (2012) for numerous insect species, this might be made possible if $C$. 50 zealandica has a high degree of phenotypic plasticity enabling it to perform under such variable 51 conditions. Certainly the initial spread of $C$. zealandica within its native range would have been a 52 consequence of the widespread cultivation of exotic host plants such as ryegrass and white clover 53 (Lefort et al. 2014). However, it would also have possibly required the species to adjust to an 54 expanded range of soil temperatures in a relatively short time frame. Consistent with this is the 55 conclusion of Stillwell and Fox (2009), that the differential responses of the seed beetle Stator 56 limbatus (Horn) to temperature, which impacted on survivorship, body size and fecundity, was due to 57 a high degree of phenotypic plasticity, rather than on genetic adaptation resulting from long-term 58 evolution. That temperature may also have had a direct influence on the differences in the distribution 59 of $C$. zealandica and C. brunneum is corroborated by the empirical study of Zerebecki \& Sorte (2011) 60 on temperature tolerance and stress proteins, which concluded that invasive species tend to live 61 within broader habitat temperature ranges and higher maximum temperatures.

62 Several enzyme systems have been successfully linked to, or are suspected to play a key role in, 63 animal physiological tolerance to temperature. Lactate dehydrogenase-B (LDH-B), for example, has 64 been linked to thermal tolerance in a killifish species (Johns \& Somero 2004, Dalziel et al. 2011). The 65 adapting kinetic properties of the cytosolic malate dehydrogenase (cMDH) enzyme have been related 66 to warm temperature adaptation in blue mussels (Fields et al. 2006), and similarly the isocitrate 67 dehydrogenase locus Idh-1 exhibits significant correlations between allele frequencies and 68 temperature in several species (for a review see Huestis et al. 2009). In invasive species, Hanski and 69 Saccheri (2006) have suggested that the metabolic enzyme system phosphoglucose-6-isomerase 70 (PGI) could play a key role in the expansion and delineation of geographical range boundaries of 
71 these species. This enzyme system sits at the intersection of the major glycolysis and glycogen

72 biosynthesis metabolic pathways, catalyzing the second step in glycolysis to energy in the form of

73 ATP to the organism (Riddock 1993). Through this unique biochemical situation, covariation patterns

74 between Pgi genotypes and individual fitness performance or life-history traits are considered likely to

75 arise (De Block \& Stock 2012). In fact, phenotypic variability of the PGI enzyme system has been

76 correlated many times to insect fitness, and several such studies on the Glanville fritillary butterfly

77 might also be relevant to success of an invasive species. For example, Haag et al. (2005) and

78 Niitepold et al. (2009) established that genetic variation in Pgi was correlated with flight metabolism,

79 dispersal rate and metapopulation dynamics in this butterfly. Additionally, Hanski and Saccheri (2006)

80 showed that the allelic composition of the PGI enzyme system had a significant effect on the growth

81 of local populations. The link between lifespan duration and the PGI phenotype showing high

82 dispersal capacity was also demonstrated (Saastamoinen et al. 2009). However, of relevance to the

83 present study, PGI genotype has been designated several times as a key enzyme candidate in insect

84 thermal tolerance to extreme temperatures (for a review see Kallioniemi \& Hanski 2011). As such, it

85 has been characterised as the best-studied metabolic enzyme in a recent review of variation in 86 thermal performance in insect populations (Sinclair 2012). Despite this, this enzyme system has 87 never been analysed in a comparative study involving invasive versus non-invasive insect species.

88 As part of a wider investigation into invasiveness of phytophagous insects, this study aimed to test 89 the hypothesis that $C$. zealandica is more tolerant of a wider range of temperature than the closely 90 related and co-occuring non-pest species $C$. bruneum, thus facilitating its establishment over a wider 91 geographic area, and to investigate whether particular PGI-genotypes are related to individual fitness 92 advantage when exposed to challenging soil temperatures.

\section{Material and methods}

\section{Insect sampling and identification}

95 Young, actively feeding, third instar larvae were collected; one population of $C$. zealandica from the

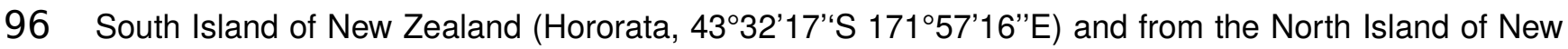




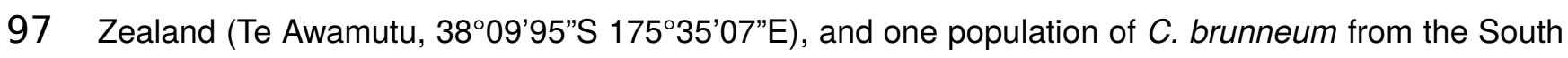

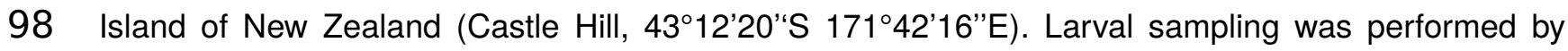

99 using a spade to turn over the upper 20 centimeters of soil at randomly chosen locations at each

100 collection site, as described in Lefort 2013. The three collection sites were respectively labeled A, B

101 and C. Larvae were identified to species based on the methodology described in Lefort et al. (2012,

102 2013). Fewer C. brunneum were found compared to $C$. zealandica. Prior to experimentation all larvae

103 were tested for amber disease, which commonly occurs in C. zealandica, as described in (Jackson et

104 al. 1993) and only healthy larvae were used.

\section{Survival and growth response to different temperature regimes}

106 Costelytra larvae usually live at an average soil depth of $10 \mathrm{~cm}$ (Wright 1989). At this depth, and

107 because of the resulting buffer effect, the yearly maximum temperatures rarely reach $20^{\circ} \mathrm{C}$ and often

108 remain above $5^{\circ} \mathrm{C}$ during the coolest months of the year in New Zealand (NZ Meteorological Service

109 1980). Because of the univoltine nature of the Costelytra species life-cycle (Atkinson and Slay 1994),

110 feeding third instar larvae are rarely exposed to soil temperatures below $10^{\circ} \mathrm{C}$ for long periods.

111 Therefore 10 and $20^{\circ} \mathrm{C}$ were used as realistically challenging temperatures within the normal soil

112 temperature range for these species, while a $15^{\circ} \mathrm{C}$ standard laboratory rearing temperature (Lefort

113 2013) was used as control.

114 The larvae of each population ( $\mathrm{n}=90$ for each $C$. zealandica population, and $\mathrm{n}=30$ for $C$. brunneum

115 population) were randomly allocated to one of the three temperature treatments at which each larva

116 was reared individually as described in Lefort et al. (2014). All larvae were fed ad libitum with

117 chopped roots of Trifolium repens (white clover).

118 Larval survival and growth measured as weight gain were recorded as measures of fitness, and

119 assessed weekly over a period of six weeks. Larvae were carefully taken out from their containers

120 and handled with soft forceps. They were weighed on a $0.01 \mathrm{~g}$ readability portable Sartorius TE412

121 digital scale. Dead larvae were collected every 24 hours and individually stored at $-80^{\circ} \mathrm{C}$ to minimise 
122 protein degradation for the electrophoretic study. At the end of the experiment, all the larvae were 123 snap frozen and similarly stored.

\section{PGI electrophoretic study}

125 The last abdominal segment of each larva was cut into small pieces on a square glass plate over ice

126 and then ground using an autoclaved plastic rod in $100 \mu$ of cooled extraction buffer (Tris- $\mathrm{HCl}, \mathrm{pH}$

127 8.0) until completely homogenized.

128 Expression of the PGI allozymes was subsequently examined by cellulose acetate electrophoresis

129 according to the manufacturers instructions (Helena Laboratories, Beaumont, US) and following 130 optimization of the method of Hebert and Beaton's (1993). The final procedure comprised of $10 \mu \mathrm{l}$ of 131 each homogenate electrophoresed on cellulose acetate plates (Titan® III 76 mm x 76 mm, Helena 132 Laboratories) in Tris-Glycine electrode buffer $\mathrm{pH} 8.5$ at a constant voltage of $200 \mathrm{~V}$ and $2 \mathrm{~mA}$ for 15 133 min. A positive heterozygote control for each Costelytra species was run on each plate. Plates were 134 immediately stained with $4 \mathrm{ml}$ of a freshly prepared PGI stain mix (Hebert and Beaton 1993). Staining 135 time was estimated visually and lasted between 1 and 2.5 minutes. Plates were then soaked for 30 136 minutes in water, blotted dry and preserved by incubating at $60^{\circ} \mathrm{C}$ for 15 minutes.

137 Each plate was subsequently digitised using a UVIDOC HD2 (Uvitec Cambridge, UK) and band 138 scoring performed by optimising the definition and aligning the different allozyme profiles obtained 139 using Adobe photoshop CS5 and OmniGraffle 5 Professional (Figure 1). For each population studied, 140 heterozygote and homozygote forms were scored for each population studied; homozygote alleles 141 were assigned as slow or fast based on their relative mobility from the loading zone (Figure 1c).

\section{Data analyses}

143 Statistical analyses to determine the effect of temperature on larval survival were carried out using

144 Fisher's exact tests. Comparisons to determine differences of larval survival rates in relation to 145 populations, allozyme(s) genotype and temperature regimes, were carried out using Fisher's exact 146 tests (Figure 2). 
147 To detect significant differences in larval growth rate among temperature treatments, growth data 148 were first analysed by analysis of variance (one way ANOVA), followed by Least Significant

149 Difference (LSD) post-hoc analysis after exclusion of larvae that died before the end of the six week 150 period.

151 For each population, a factorial ANOVA was carried out to test if the interaction term, temperature

152 treatment $x$ PGI genotype, had an effect on larval growth. When a significant temperature treatment $x$

153 PGI genotype effect was detected, follow-up T-tests were performed to compare the average growth

154 of each PGI genotype under each of the three temperature regimes.

155 Statistical tests were conducted with R software (R Development Core Team 2009) and GenStat ${ }^{8}$ 156 (GenStat 14, VSN International Ltd, UK).

\section{Results}

158 Few larvae died during the course of the experiment and were not used in the analysis. All surviving 159 larvae produced scorable electrophoretic patterns. Sample sizes are summarized in Table 1. The 160 electrophoretic study revealed the existence of only one PGI-locus in both Costelytra species (Figure 161 1). The genotypes along with their distribution in each temperature treatment are summarized in 162 Table 1.

163 There were no significant differences in larval survival under the different temperature treatments for

164 populations A and C. For population B (C. zealandica collected from the North Island of New 165 Zealand), survival was significantly higher at $10^{\circ} \mathrm{C}\left(100 \%\right.$ survival) than it was at $20^{\circ} \mathrm{C}(73 \%$ survival $)$ 166 (Fisher's exact test, $\mathrm{P}=0.0046$ ) (Figure 2). However, the weight gain of that population was not 167 significantly different for any temperature treatment (Figure 3).

168 In contrast, the weight gain of South Island C. zealandica (site A) significantly increased under the 169 highest temperature of $20^{\circ} \mathrm{C}$, compared to the lowest temperature (Figure 3), while C. brunneum 
170 gained, on average, significantly more weight at $15^{\circ} \mathrm{C}$ compared to the more challenging extremes 171 (Figure 3).

172 A significant interaction between temperature treatment and PGI genotype on larval growth was only 173 detected for C. zealandica collected from the South Island (sample site A) (Table 2).

174 In this population, at $10^{\circ} \mathrm{C}$, homozygotes $\mathrm{H} 1$ (fast allele) gained significantly more weight compared 175 to homozygotes $\mathrm{H} 2$ (slow allele) (Figure 4). On the other hand, under the higher temperature regime 176 tested, homozygotes $\mathrm{H} 2$ gained significantly more weight at the $1 \%$ level of significance compared 177 with homozygotes, $\mathrm{H} 1$, at $20^{\circ} \mathrm{C}$ and heterozygotes, $\mathrm{HE}$, at $15^{\circ} \mathrm{C}$ (Figure 4).

178

\section{Discussion}

180 The main objective of this study was to investigate the suggestion proposed by Hanski and Saccheri

181 (2006) that the Pgi gene may be strongly implicated in 'the expanding front of invasive species'.

182 Towards this the present study aimed at testing whether a relationship between the PGI-genotypes of

183 Costelytra species and their fitness response under different temperature regimes exists. However, 184 the results here did not consistently indicate such correlation across all the populations tested, 185 although significant effects of temperature on the larval growth and/or survival of the two species 186 were detected.

187 Consistent with the latter, Lefort (2013) had previously shown that $C$. zealandica had an improved 188 survival rate at lower rather than at higher temperatures. In the present study this was only apparent 189 for the North Island population, having better survival at $10^{\circ} \mathrm{C}$ compared with the highest temperature 190 of $20^{\circ} \mathrm{C}$. This discrepancy, of no effect here for the South Island population, could be due to the 191 relatively short length of this study compared to the 17 weeks of Lefort, 2013. Additionally, the North 192 Island larvae used here could have been more sensitive to the experimental conditions, because they 193 were subject to a higher degree of disturbance and stress associated with longer transport from the 194 sample site to the laboratory. 
195 In a similar way to larval survival, the temperature effect on larval growth was significantly different

196 between the two populations of $C$. zealandica. Weight gain of the larvae collected from the South

197 Island was significantly depressed by low temperature (i.e. $10^{\circ} \mathrm{C}$ ), whereas this effect was not

198 detected in the larvae collected from the North Island. Some degree of genetic divergence between

199 the two populations studied might exist and explain this disparity. For example, the cosmopolitan

200 Drosophila melanogaster Meigen exhibits complex patterns of genetic variation between populations

201 that have allowed it to successfully establish worldwide under extremely diverse thermal

202 environments (Hoffmann et al. 2003, Morgan \& Mackay 2006). There is in fact some evidence of

203 genetic divergence within C. zealandica based on the ITS1 rDNA sequences reported by Richards et

204 al. (1997), particularly between North Island and South Island populations. Furthermore, adult

205 specimens of $C$. zealandica have been reported to be larger in the North Island (Travis Glare,

206 personal communication, Bio-Protection Research Centre NZ). In addition, Lefort et al. (2014) have

207 demonstrated that host-race formation in this species might have been instrumental to its invasion

208 success. This may have contributed to the establishment of even further genetic divergence between

209 C. zealandica populations throughout New Zealand since that reported by Richards et al. (1997),

210 although in the present study both populations were collected from exotic pastures mostly composed

211 of the same host plants.

212 The non-pest species C. brunneum, in contrast to $C$. zealandica, showed significantly impaired, but

213 not lethally detrimental, larval growth under the most challenging temperature regimes, particularly at

$21420^{\circ} \mathrm{C}$. Even though very little is known about the actual distribution of $C$. brunneum, this species

215 seems to prefer mid to high altitudinal ranges (Hoy \& Given 1952, Given 1966). In those regions soil

216 temperatures are likely be similar to the averages recorded in the coldest southern locations of New

217 Zealand, e.g. Invermay's yearly average soil temperature ranged between 15 and $2.9^{\circ} \mathrm{C}(\mathrm{NZ}$

218 Meteorological Service 1980)). These observations corroborate the fact that this non-invasive species

219 is less tolerant than C. zealandica to challenging temperatures, particularly higher temperatures,

220 which would be consistent with its failure to extend its geographical range as has its invasive

221 congener.

222 Because of its potential impact on the functional properties of metabolic enzymes (Kallioniemi \&

223 Hanski 2012), temperature is often characterised as a key environmental factor affecting the growth 
224 and survival of poikilothermic organisms (Kallioniemi \& Hanski 2012, Sinclair et al. 2012). Hence, the

225 interest in the expression of various forms of these enzymes, their allozymes or isoenzymes, has

226 considerably increased over recent decades (Karl et al. 2010). Amongst these, PGI has been

227 described as a highly polymorphic enzyme system in numerous taxa (Kallioniemi \& Hanski 2012). For

228 instance, seven alleles were detected for the pgi gene in Melitaea cinxia (Linnaeus), the Glanville

229 Fritillary butterfly, and many coleopteran species possess over three alleles for this gene (e.g.

230 Nahrung \& Allen 2003, Dahlhoff \& Rank 2007). Such polymorphism provides potential for species to

231 vary in their ecological response, including their thermal tolerance (Kallioniemi \& Hanski 2011). In the

232 present study, the electrophoretic profiles revealed the expression of two alleles at only one PGI-

233 locus for these Costelytra species (Figure 1). However, as the resolution using cellulose acetate

234 technology is not high, there is the possibility that detection of additional alleles was missed because

235 of poor migration and separation of the various allozymes on the gel, or that allozymes of different

236 loci have a similar or highly similar net charge rendering them indistinguishable under these

237 electrophoretic conditions. Alternative higher resolution methods such as mass spectrometry, or

238 genetic and genomic methods may be needed to confirm this enzyme system is not as polymorphic

239 as it appears in other insect species.

240 It was expected that if PGI-associated metabolic pathways provide a greater ability to adapt to a

241 wider range of temperatures, heterozygote individuals for this enzyme system would have displayed

242 better weight gain and survival rates under challenging temperatures than homozygotes. Such results

243 would be consistent with Watt's studies $(1977,2003)$ of the PGI enzyme system in Colias butterflies,

244 which reported heterozygotic advantage with respect to several life-history and fitness traits in this

245 species. The results of the present study showed that homozygote genotypes $\mathrm{H} 1$ gained more weight

246 under the lowest temperature tested, and also suggested higher fitness in homozygotes $\mathrm{H} 2 \mathrm{under}$

247 higher temperatures in the C. zealandica collected from the New Zealand South Island site. However,

248 despite these counterintuitive results, it is important to bear in mind that extensive studies on PGI

249 expression in several butterfly species have demonstrated that enhanced individual performances are

250 correlated with different allelic compositions for various life-history traits. For instance, Karl et al.

251 (2008, 2009) demonstrated that there was enhanced larval and pupal growth and development in

252 heterozygote genotypes PGI 2-3 in the butterfly Lycaena tityrus, whereas cold stress resistance in the 
253 same species was associated with a different PGI genotype. Hence, heterozygote advantage may not 254 systematically apply to this enzyme system. Furthermore, the two above studies by Karl et al. (2008, 255 2009), could suggest that allelic variability in the PGI enzyme system is expected to be higher in 256 invasive species compared with non-invasive ones, since successful invaders often display high 257 individual performance in many different fitness and life history traits. Therefore, if the low allelic 258 variability observed in $C$. zealandica in this study is the result of a misinterpretation of the 259 electrophoresis profiles, this could in part explain why no consistent relationship between individual 260 larval fitness responses and PGI genotypes between the two populations of the invasive species 261 were detected.

262 Additionally, the fact that a significant relationship was detected between the selected life-history 263 traits and the PGI genotypes in only one population of the species studied may be due to the 264 experimental design being driven by the need to perform the temperature experiments prior to 265 sacrificing the larvae for the electrophoretic study. This compromised design, using individual insects 266 of unknown allelic composition, has resulted in small and unbalanced sample sizes as shown in 267 Table 1.

268 In conclusion, the present study has been unable to support the hypothesis that the Costelytra spp. 269 response to challenging temperatures was indeed related to the pgi gene and more precisely with 270 PGI allozyme forms expressed by this gene. Small and unbalanced sample size, with respect to 271 allele types, along with the low allelic variability in Costelytra species and the resulting difficulties to 272 interpret the electrophoretic profiles could explain why no relationship between this gene and thermal 273 tolerance in the studied species was found. Indeed, other studies have established a link between 274 thermal tolerance and the pgi gene in various species, including cnidarians (Zamer \& Hoffmann 275 1989), beetles (Dahlhoff \& Rank 2000) and moth and butterfly species (Karl et al. 2009, He 2010). It 276 is also important to note that the present study investigates the underground life-stage of the targeted 277 species. The thermal dynamics of these insects are therefore somehow different from those of 278 aboveground insects such as adult willow leaf beetles or butterflies that experience a much wider 279 range of temperatures on a daily basis than underground life-stages, and which have until now 280 served as model systems for studying the effects of the PGI system on life history traits. In addition, 281 this study was centered on insect survival and growth, while other life history and fitness traits, 
282 relevant to insect invasion success such as for instance dispersal capacity and mating/offspring 283 successes, might also be affected by the PGI system. For these reasons, we believe that it is still 284 possible that differential expression of this gene could be involved in the invasion success of some 285 insects, even maybe so in the adult stage of $C$. zealandica, allowing them to extend their range over 286 wider geographical areas compared to other species.

287 Several studies have successfully linked various forms of PGI allozymes with the expression of heat 288 shock proteins (Hsps), which play important roles in thermal tolerance by reducing stress-induced 289 protein aggregation (Dahlhoff \& Rank 2000, Dahlhoff \& Rank 2007, McMillan 2005). Additional 290 investigations on Hsps expression in Costelytra spp., rather than on the PGI enzyme system itself,

291 could help to establish whether the tolerance to challenging soil temperatures observed in the 292 invasive species C. zealandica somehow relates to the PGI enzyme system. The sympatric nature of 293 the non-invasive and invasive species studied here provided a valuable opportunity to investigate PGI 294 as a marker of invasiveness. There are many other such species pairs such as the queensland and 295 lesser queensland fruit flies that would serve the same purpose. Therefore we strongly encourage 296 researchers to replicate the experiments described in this paper using such invasive/non-invasive 297 species pairs and to confirm whether or not a relationship exists between the PGI enzyme system 298 and insect fitness response to temperature and with the potential to be used as a measure of 299 environmental tolerance in invasive species.

\section{Acknowledgments}

301 We would like to thank Richard Townsend and St Andrew's College of Christchurch for granting 302 access to the collection sites, and Derrick Wilson for his help with the collection of the larvae from the 303 North Island. Finally we would like to thank the reviewer for his constructive comments and advice on 304 the initial manuscript. 


\section{References}

306

307

308

309

310

311

312

313

314

315

316

317

318

319

320

321

322

323

324

325

326

327

328

329

330

331

332

333

334

335

336

337

338

339

340

341

342

343

344

345

346

Atkinson D \& Slay M (1994) Winter management of grass grub (Costelytra zealandica (White)). New Zealand Journal of Agricultural Research 37:553-558.

Bale JS, Masters GJ, Hodkinson ID, Awmack C, Bezemer TM, Brown VK, Butterfield J, Buse A, Coulson JC, Farrar J, et al. (2002) Herbivory in global climate change research: direct effects of rising temperature on insect herbivores. Global Change Biology 8:1-16.

Clarke A (2003) Costs and consequences of evolutionary temperature adaptation. Trends in Ecology \& Evolution 18:573-581.

Dahlhoff EP \& Rank NE (2007) The role of stress proteins in responses of a montane willow leaf beetle to environmental temperature variation. Journal of Biosciences 32:477-88.

Dahlhoff EP \& Rank NE (2000) Functional and physiological consequences of genetic variation at phosphoglucose isomerase: heat shock protein expression is related to enzyme genotype in a montane beetle. Proceedings of the National Academy of Sciences 97:10056-10061.

Dalziel AC, Rogers SM \& Schulte PM (2009) Linking genotypes to phenotypes and fitness: how mechanistic biology can inform molecular ecology. Molecular Ecology 18:4997-5017.

De Block M \& Stoks R (2012) Phosphoglucose isomerase genotype effects on life history depend on latitude and food stress. Functional Ecology 26:1120-1126.

East R, King PD \& Watson RN (1981) Population studies of grass grub (Costelytra zealandica) and black beetle (Heteronychus arator) (Coleoptera: Scarabaeidae). New Zealand Journal of Ecology 4:5664.

Fields PA, Rudomin EL \& Somero GN (2006) Temperature sensitivities of cytosolic malate dehydrogenases from native and invasive species of marine mussels (genus Mytilus): sequencefunction linkages and correlations with biogeographic distribution. The Journal of experimental biology 209:656-67.

Folguera G, Mensch J, Muñoz JL, Ceballos SG, Hasson E \& Bozinovic F (2010) Ontogenetic stagedependent effect of temperature on developmental and metabolic rates in a holometabolous insect. Journal of Insect Physiology 56:1679-84.

Given BB (1966) The genus Given (Melolonthinae: Coleoptera) including descriptions of four new species. New Zealand Journal of Science 9:373-390.

Haag CR, Saastamoinen M, Marden JH \& Hanski I (2005) A candidate locus for variation in dispersal rate in a butterfly metapopulation. Proceedings. Biological sciences / The Royal Society 272:2449-56.

Hanski I \& Saccheri I (2006) Molecular-level variation affects population growth in a butterfly metapopulation. PLoS biology 4:e129.

He S (2010) Pest risk assessment of light brown apple moth, Epiphyas postvittana (Lepidoptera: Tortricidae) using climate models and fitness-related genetic variation. Master thesis. Lincoln University, New Zealand.

Hebert PDN \& Beaton MJ (1993) Methodologies for allozyme analysis using cellulose acetate electrophoresis - a practical handbook. Helena Laboratories, Beaumont.

Hoffmann AA, Sørensen JG \& Loeschcke V (2003) Adaptation of Drosophila to temperature extremes: bringing together quantitative and molecular approaches. Journal of Thermal Biology 28:175-216.

Hoy JM \& Given BB (1952) A Revision of the Melolonthinae of New Zealand. Part II: Final instar larvae. Bulletin of New Zealand Department of Scientific and Industrial Research 102:1-137.

PeerJ reviewing PDF | (v2014:08:2508:1:1:NEW 31 Oct 2014) 
Huestis DL, Oppert B \& Marshall JL (2009) Geographic distributions of Idh-1 alleles in a cricket are linked

Papanikolaou NE, Milonas PG, Kontodimas DC, Demiris N \& Matsinos YG (2013) Temperaturedependent development, survival, longevity, and fecundity of Propylea quatuordecimpunctata (Coleoptera: Coccinellidae). Arthropod Biology 106:228-234.

R Development Core Team 2011. R: A language and environment for statistical computing, version 2.12.1. Vienna, Austria, R Foundation for Statistical Computing. http://www.R-fproject.org/.

Richards NK, Glare TR, Hall DCA \& Bay H (1997) Genetic variation in Grass Grub, Costelytra zealandica, from several regions. Genetics:338-343. 
392

393

394

395

396

397

398

399

400

401

402

403

404

405

406

407

408

409

410

411

412

413

Riddock BJ (1993) The adaptive significance of electrophoretic mobility in phosphoglucose isomerase (PGI). Biological Journal of the Linnean Society 50:1-17.

Saastamoinen M, Ikonen S \& Hanski I (2009) Significant effects of Pgi genotype and body reserves on lifespan in the Glanville fritillary butterfly. Proceedings. Biological sciences / The Royal Society 276:1313-22.

Sinclair BJ, Williams CM \& Terblanche JS (2012) Variation in thermal performance among insect populations. Physiological and Biochemical Zoology 85:594-606.

Stillwell CR \& Fox CW (2009) Geographic variation in body size, sexual size dimorphism and fitness components of a seed beetle: local adaptation versus phenotypic plasticity. Oikos 118:703-712.

Wallner WE (1987) Factors affecting insect population dynamics: differences between outbreak and nonoutbreak species. Annual review of Entomology 32:317-340.

Watt WB (2003) Mechanistic studies of butterfly adaptations. Ecology and evolution taking flight: butterflies as model systems (Eds CL Boggs, WB Watt \& Ehrlich PR) University of Chicago Press, New York.

Watt WB (1977) Adaptation at species loci. I. Natural selection on phosphoglucose isomerase of Colias butterflies: biochemical and population aspects. Genetics 87:177-194.

Wright $\mathrm{P}$ (1989) Selection of entomogenous nematodes to control grass grub and porina in pasture. $\mathrm{PhD}$ thesis. Lincoln University, New Zealand.

Zamer WE \& Hoffmann RJ (1989) Allozymes of glucose-6- phosphate isomerase differentially modulate pentose-shunt metabolism in the sea anemone Metridium senile. Proceedings of the National Academy of Sciences 86:2737-2741.

Zerebecki RA \& Sorte CJB (2011) Temperature tolerance and stress proteins as mechanisms of invasive species success. PloS one 6:e14806. 


\section{Figure 1}

Example of scoring of a cellulose acetate plate.

Where (a) is an original picture of the plate, (b) is a definition optimisation and alignment of the allozyme profiles via Adobe Photoshop CS5 and OmniGraffle 5 Professional and (c) is a representation of the allozyme profiles. $\mathrm{H} 1$, fast allele detected - homozygote $1 ; \mathrm{H} 2$, slow allele detected - homozygote 2; HE, fast and slow allele detected - heterozygote; SLD, sample loading zone.

(a)

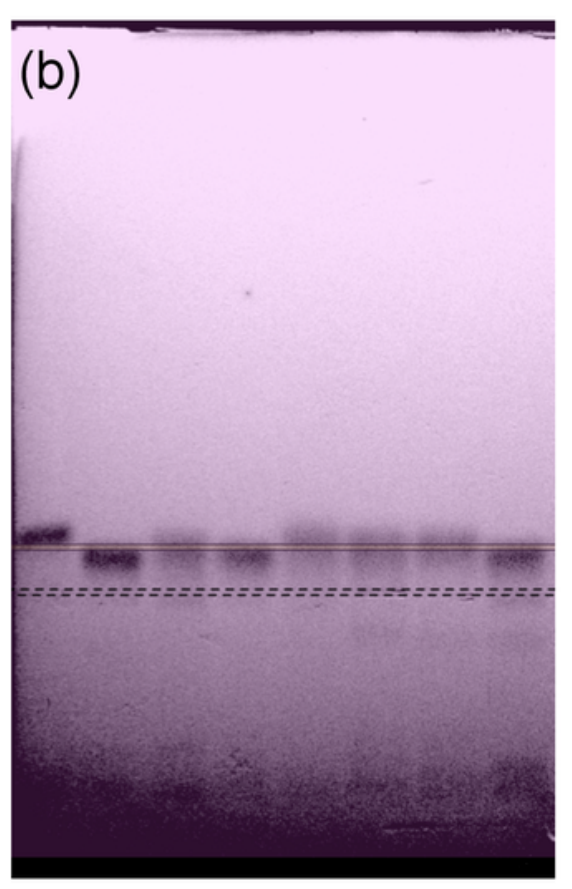

(c)

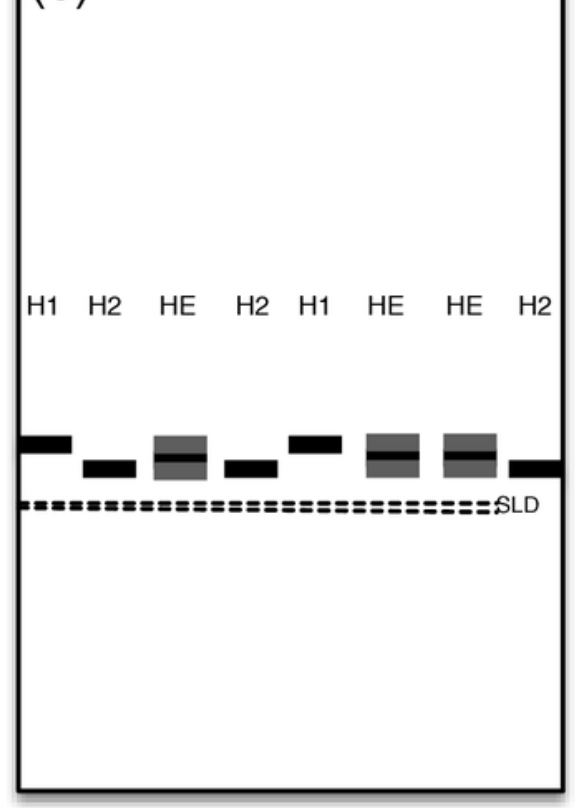


Figure 2

Percentage of larval survival of Costelytra zealandica and C. brunneum after 6 weeks of treatment under different temperatures $\left(10,15\right.$ and $\left.20^{\circ} \mathrm{C}\right)$.

Details of larval survival (dark grey)/mortality rates (light grey) observed for each PGIgenotype detected in each population. 

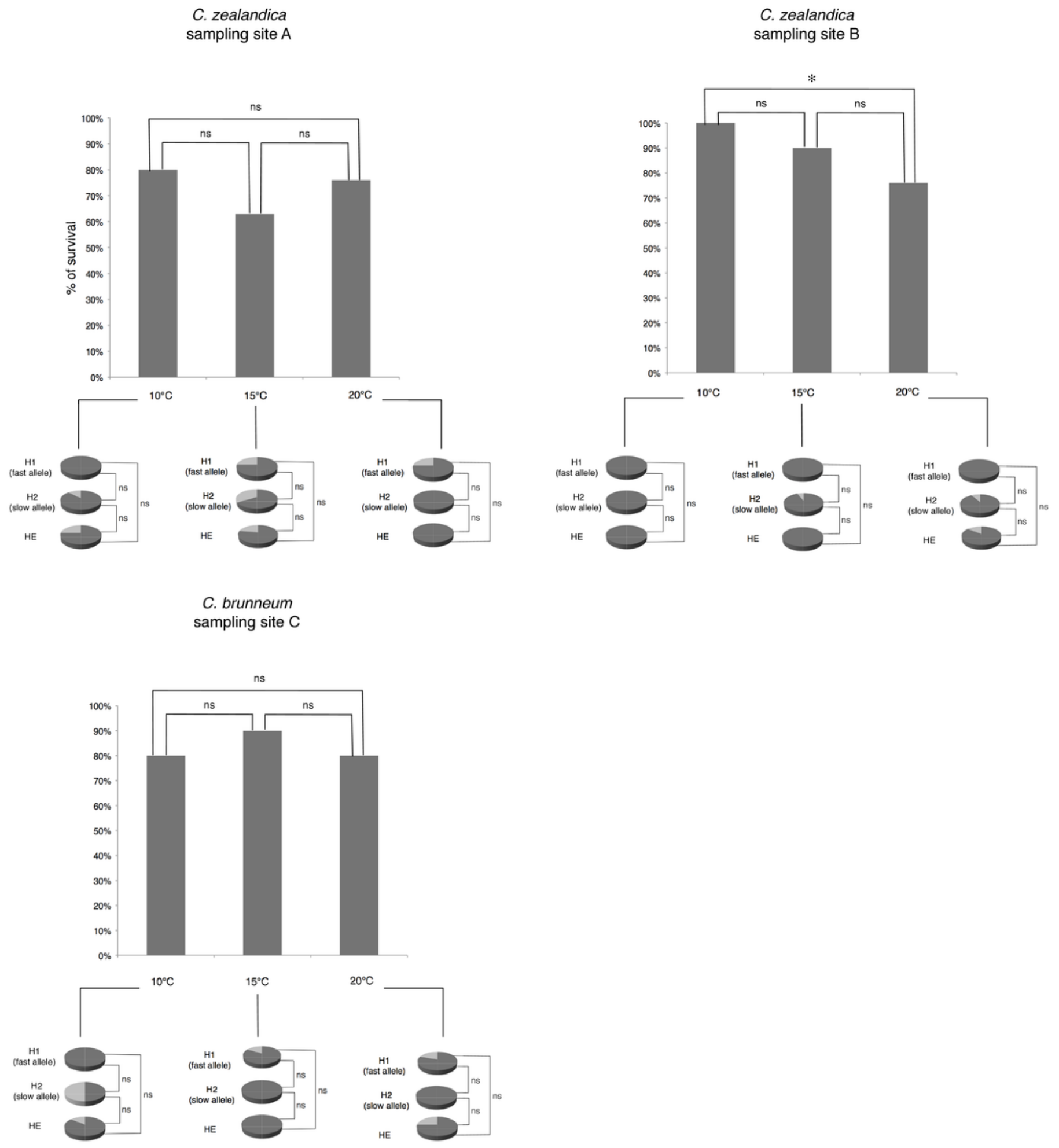

C. brunneum

sampling site $\mathrm{C}$ 
Figure 3

Average weight gains of the surviving larvae of two populations of Costelytra zealandica and one population of $C$. brunneum after 6 weeks of treatment under different temperatures.

Vertical bars represent the 5\% Least Significant Difference (LSD); LSDs $=0.0175,0.0146$ and 0.0299 for the populations from sample sites A, B and C respectively.

$10^{\circ} \mathrm{C}$

- $15^{\circ} \mathrm{C}$

- $20^{\circ} \mathrm{C}$

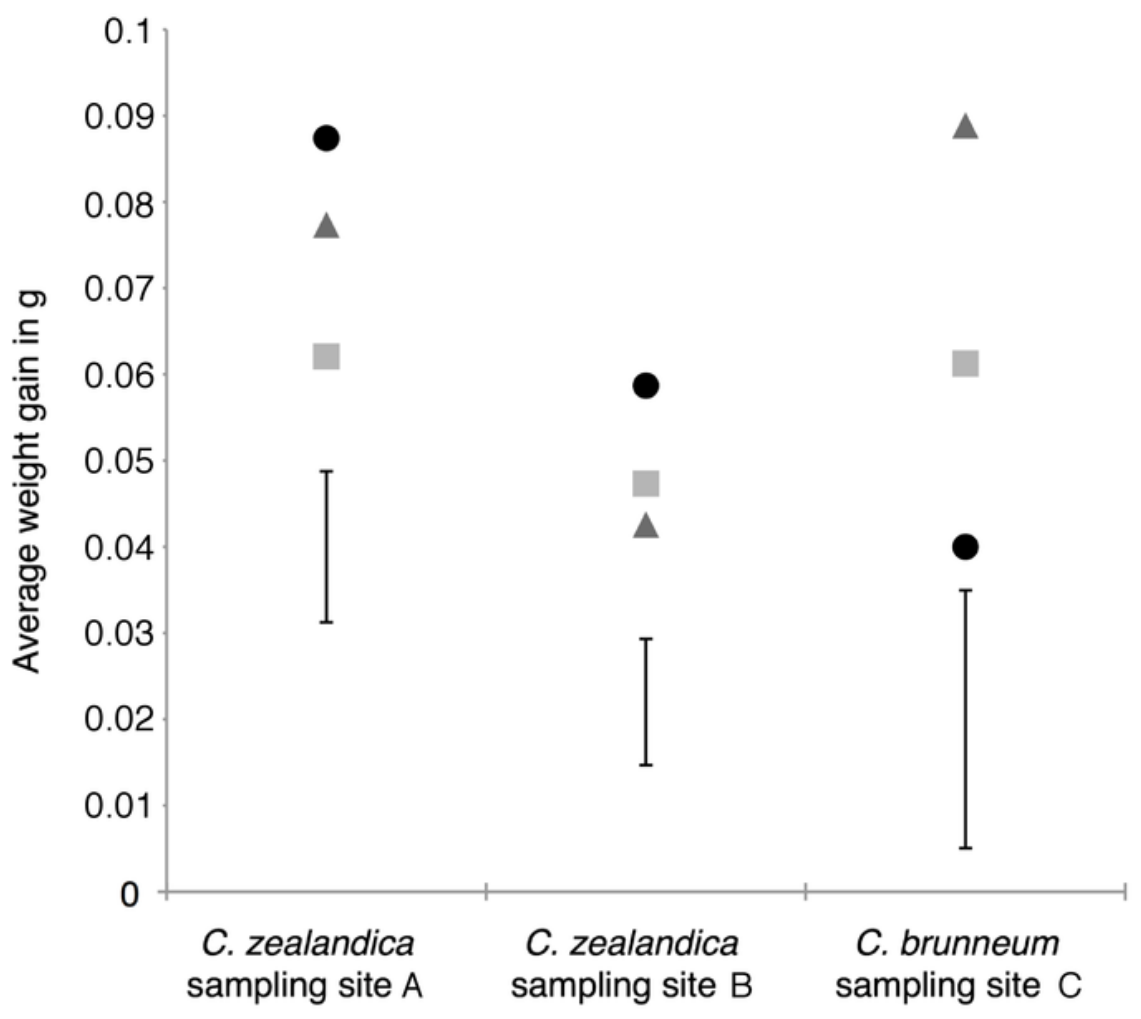




\section{Figure 4}

Average percentage weight gain in Costelytra zealandica larvae collected from the New Zealand South Island (sample site A).

Weight gain is presented for each PGI genotype ( $\mathrm{H} 1$, fast allele - homozygote $1 ; \mathrm{H} 2$, slow allele - homozygote 2; $\mathrm{HE}$, both alleles- heterozygote), after six weeks at 10,15 and $20^{\circ} \mathrm{C}$. Horizontal bars represent SE. All pairwise comparisons were performed using Student's Ttest. Asterixes indicate significant $(*)$ (Student's T-test, $\mathrm{P}<0.05)$, or marginally at $1 \%$ level of significance (marginaly *) differences (Student's T-test, $\mathrm{P}<0.10$ ).

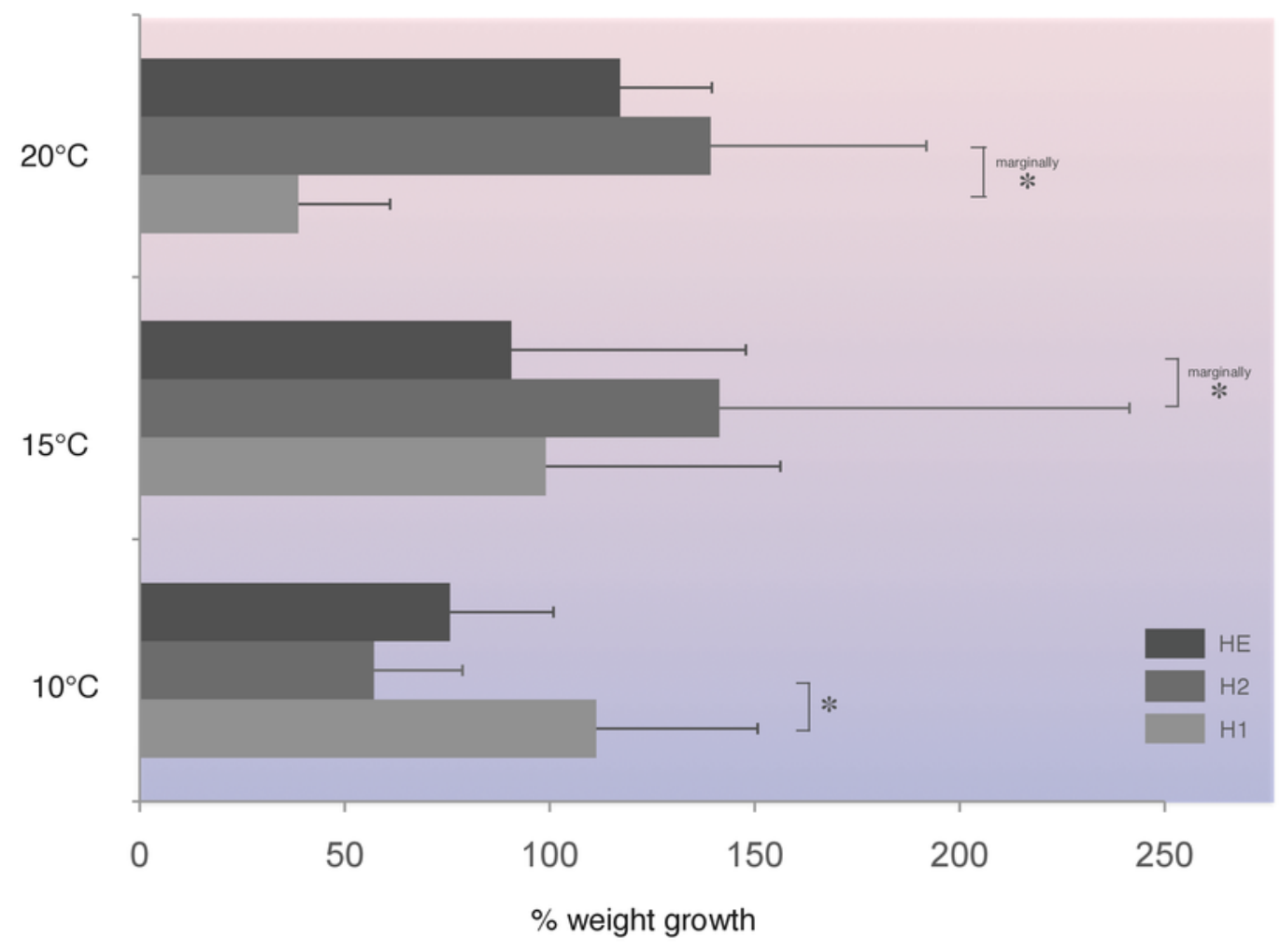




\section{Table $\mathbf{1}$ (on next page)}

PGI phenotypes detected by cellulose acetate electrophoresis in Costelytra zealandica and $C$. brunneum and their effective distribution in each temperature treatment. 


\section{PeerJ Reviewing Manuscript}

Table 1. PGI phenotypes detected by cellulose acetate electrophoresis in Costelytra zealandica and $C$. brunneum and their effective distribution in each temperature treatment.

\begin{tabular}{|c|c|c|c|}
\hline & $\begin{array}{c}\text { H1 } \\
\text { (homozygote - fast allele) }\end{array}$ & $\begin{array}{c}\text { H2 } \\
\text { (homozygote - slow allele) }\end{array}$ & $\begin{array}{c}\text { HE } \\
\text { (heterozygote) }\end{array}$ \\
\hline $\begin{array}{l}\text { C. zealandica } \\
\text { (sampling site A) }\end{array}$ & $\begin{array}{c}\mathbf{n}=\mathbf{1 4} \\
\text { (respectively } \mathrm{n}=8,3 \text { and } 3 \text { at } 10,15 \text { and } 20^{\circ} \mathrm{C} \text { ) }\end{array}$ & $\begin{array}{c}\mathbf{n}=\mathbf{1 6} \\
\left(\text { respectively } \mathrm{n}=7,2 \text { and } 7 \text { at } 10,15 \text { and } 20^{\circ} \mathrm{C} \text { ) }\right.\end{array}$ & $\begin{array}{c}\mathbf{n}=\mathbf{3 6} \\
\text { (respectively } \mathrm{n}=9,14 \text { and } 13 \text { at } 10,15 \text { and } 20^{\circ} \mathrm{C} \text { ) }\end{array}$ \\
\hline $\begin{array}{l}\text { C. zealandica } \\
\text { (sampling site B) }\end{array}$ & $\begin{array}{c}\mathbf{n}=\mathbf{1 3} \\
\text { (respectively } \mathrm{n}=5,3 \text { and } 5 \text { at } 10,15 \text { and } 20^{\circ} \mathrm{C} \text { ) }\end{array}$ & $\begin{array}{c}\mathbf{n}=\mathbf{4 3} \\
\text { (respectively } \mathrm{n}=17,15 \text { and } 11 \text { at } 10,15 \text { and } 20^{\circ} \mathrm{C} \text { ) }\end{array}$ & $\begin{array}{c}\mathbf{n}=\mathbf{2 3} \\
\left(\text { respectively } \mathrm{n}=8,9 \text { and } 6 \text { at } 10,15 \text { and } 20^{\circ} \mathrm{C} \text { ) }\right.\end{array}$ \\
\hline $\begin{array}{l}\text { C. brunneum } \\
\text { (sampling site C) }\end{array}$ & $\begin{array}{c}n=10 \\
\text { (respectively } n=1,5 \text { and } 4 \text { at } 10,15 \text { and } 20^{\circ} \mathrm{C} \text { ) }\end{array}$ & $\begin{array}{c}\mathbf{n}=\mathbf{4} \\
\text { (respectively } \mathrm{n}=1,2 \text { and } 1 \text { at } 10,15 \text { and } 20^{\circ} \mathrm{C} \text { ) }\end{array}$ & $\begin{array}{c}\mathbf{n}=\mathbf{1 1} \\
\text { (respectively } n=6,2 \text { and } 3 \text { at } 10,15 \text { and } 20^{\circ} \mathrm{C} \text { ) }\end{array}$ \\
\hline
\end{tabular}


Table 2 (on next page)

Factors affecting Costelytra spp. larval growth rate and their interactions. 


\section{PeerJ Reviewing Manuscript}

Table 2. Factors affecting Costelytra spp. larval growth rate and their interactions.

\begin{tabular}{|c|c|c|c|c|c|c|c|c|c|c|c|c|}
\hline Temperature & 5.5472 & 1 & 0.0218 & + & 1.6051 & 1 & 0.2205 & ns & 2.4125 & 1 & 0.1247 & ns \\
\hline Temperature $x$ PGI genotype & 7.6109 & 2 & 0.0011 & $\#$ & 0.1573 & 2 & 0.8555 & ns & 1.8284 & 2 & 0.1679 & ns \\
\hline
\end{tabular}

